\title{
Linkage Between Traditional Architectural Elements Representing Regionalism and Achieving Salutogenesis
}

\author{
Ishita Mouri Rahman
}

\begin{abstract}
Cultural inferences are lost in the context of city, which can be reestablished with conscious design decisions by the architect and conscious house dwellers. Delving into those regionally established architectural elements found in Bangladesh or in the South East Asian climate, connections are found which are crucial to achieve the modern green building. Traditional architecture addresses sustainability. Salutogenesis is an approach coined by Aaron Antonovsky focusing on factors that support human health and well-being. This study draws the linkages between traditional architectural practices and achieving salutogenesis.
\end{abstract}

Rundown phrases- Green building, regionalism, salutogenesis, traditional architecture

\section{I.INTRODUCTION}

The architecture of a place adorned in regionalism expresses the identity of that region, culture and people. It can be stated, the more architecture loses its regional touch, the more it is deviating from its identity. Intervention of the architect can play an effective role in creating harmony in chaos, conformity in discord within the urban cacophony. Adopting climate-responsive design, use of local and sustainable materials and water harvesting techniques ensure the long term well being of the dwellers. This study aims to establish the fact that the salutogenesis concept coined by Aaron Antonovsky, the green building principles and incorporation of traditional architecture principles of the region concerned whichever may that be, are all unanimously creating better built environments.

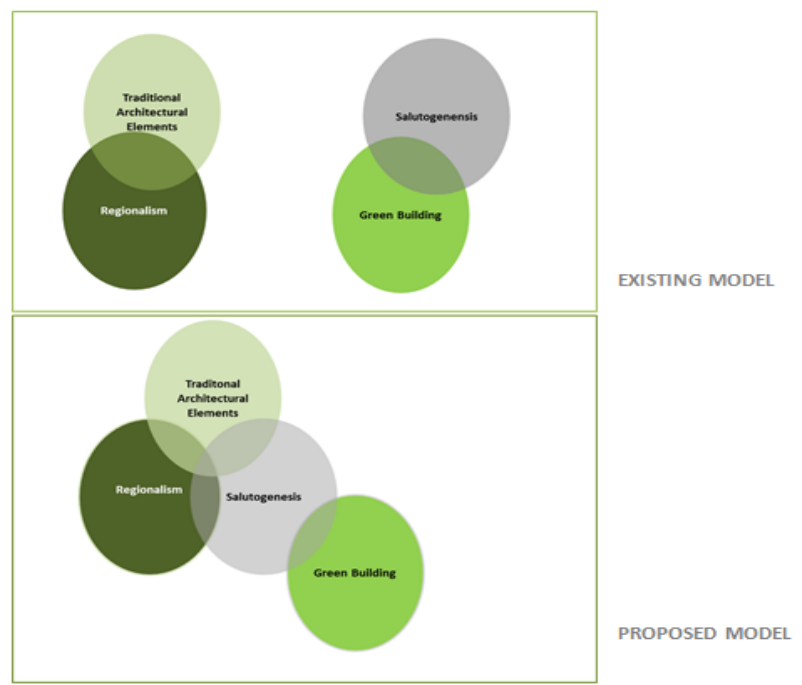

Revised Manuscript Received on July 18, 2019.

Ishita Mouri Rahman, Institute of Energy, Dhaka University, Bangladesh (E-mail: ishitarahman@hotmail.com)

\section{METHODOLOGY AND METHODS}

Primary data is collection through Questionnaire formation and survey of dwellers of a present day building in Dhaka, Bangladesh.

Literature study is done on the traditional architecture of Bangladesh and the Indian sub-continent region and present time architectural works in Bangladesh and drawing a link between the two. Study is done on green building guidelines of LEED and the concept of salutogenic architecture.

Analysis is done with the primary and secondary data.

\section{PURPOSE STATEMENT}

The traditional architectural elements representing regionalism are effective in achieving salutogenesis

\section{OBJECTIVE}

Keeping salutogenesis in the forefront and how it can be achieved in design, the aim of this study is to unfold a layer of traditional wisdom which are effective.

In exploration of the various traditional architectural elements, anthropologically speaking, and exploring a present day case study where traditional values are injected into the design of the building.

This is a quest to draw a linkage between old ideologies' relevance to achieve new concepts.

\section{SIGNIFICANCE OF THE STUDY \& RESULTS}

Architecture of a place speaks of the time, place, tradition, culture of the place. There is a reason for why the architecture varies from climate to climate and region to region. The significance of this study is to establish the fact that traditional beliefs and architectural practices in this Bengali and South East Asian region are still and will always be relevant in order to achieve salutogenesis and create modern day green building. It delves into the importance of holding onto our roots and drawing the inference that the traditional wisdom is our guide.

\section{Regionalism}

Regional priority addressing geography specific environmental priorities gets rewarded by up to 4 points in LEED Green building Certification. 


\section{LINKAGE BETWEEN TRADITIONAL ARCHITECTURAL ELEMENTS REPRESENTING REGIONALISM AND ACHIEVING SALUTOGENESIS}

Western impact on the architecture of this region is on the rise in Bangladesh. Fixed glass window is a concept adopted from western countries which responds to the climate of those regions mainly with cold wind and snowfall or heat waves in dessert zones. Such projects have a high cost in maintenance with mechanical cooling system and high electricity consumption.

We need not discard a layer of the cultural context and regional essence while laying down our plans. A western model would not work in terms of regional climate or in terms of addressing the Bengali cultural needs.

Climate and culture responsiveness need to be addressed.

\section{Salutogenesis}

This study draws the linkages between traditional architectural practices and achieving salutogenesis

Salutogenesis is an approach coined by Aaron Antonovsky focusing on factors that support human health and well-being. As defined by the World Health Organization (WHO) health is a state of complete physical, mental and social well-being and not merely the absence of disease or infirmity.

The concept of salutogenensis can be incorporated in buildings through design decisions which are good for the dwellers physical and mental health. Salutogenesis is being incorporated in health care premises in recent times, and also needs to be made an integral part of all architectural edifice.

\section{Pathogenesis vs salutogenesis:}

Broadly, salutogenensis is the opposite of pathogenesis. Pathogenesis is the development of a disease and the chain of events leading to that disease. Salutogenesis is the model which helps in health promotion, disease prevention and cure. It is one degree ahead because salutogenesis enables well being.

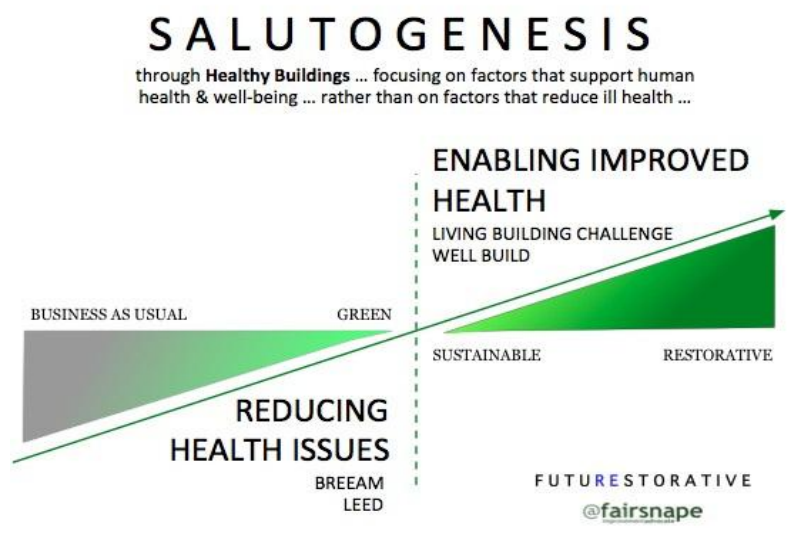

\section{image: www.fairsnape.com}

Design can play the role of a vehicle that promotes salutogenesis. For instance, a poorly ventilated and dark house will result in bad health and depressive condition for the dwellers. While on the other hand, when a house is designed with provisions for ample sunlight and air circulation, the dwellers are likely to have a healthy body and mind. As a fact, Vitamin D found directly through exposure to sunlight plays a role in stronger bones and stronger immunization in the dwellers and wards off a list of ailments.

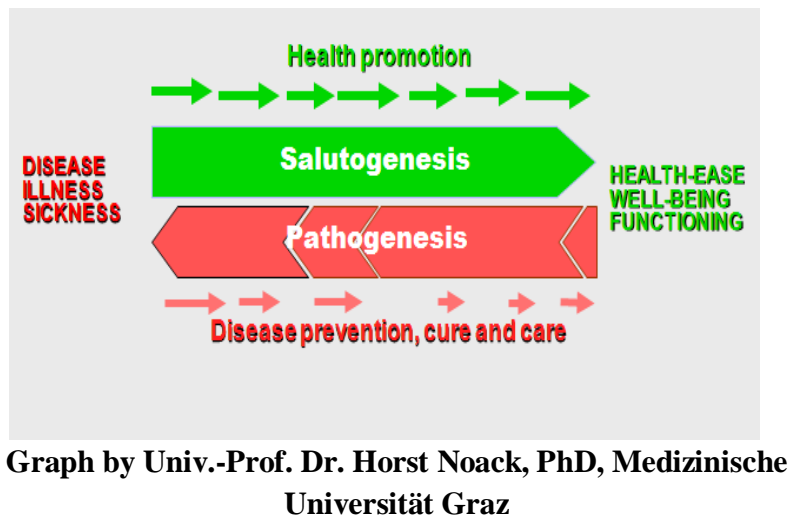

Green building

In current times, there is a escalation in green buildings in order to reduce our energy consumptions along with costs. It significantly plays a role in reducing national energy consumption level and in turn save energy on a global level.

These energy, water and resource efficient buildings are environmentally responsive and actualizing a sustainable community.

\section{Enabler:}

A good design can enable an enhanced indoor environment quality which can gain 15 points in the LEED (Leadership in energy and environmental Design) rating point system with the input of thermal comfort, daylight and views and increased ventilation.

Newer concepts of sharing parking space with neighbours are introduced to maximize the open space according to LEED. Reducing impervious cover and increasing on site infiltration for storm water control is a must. Water use reduction by $20 \%$ is required to achieve green building. Reducing mechanical ventilation, use of electricity and water consumption is the aim. Both natural ventilation and natural lighting goals achievement are recommended for achieving green building standards even in non domestic buildings. Regularly occupied spaces must be day lighted.

Green building checklist

$\begin{array}{ll}\text { - } & \text { Energy Conservation and Efficiency } \\ \text { - } & \text { Materials and Resources } \\ \text { - } & \text { Indoor Air Quality } \\ \text { - } & \text { Water Conservation and Management } \\ \text { - } & \text { Cost Effectiveness of Construction } \\ \text { - } & \text { Presentation and Other Considerations }\end{array}$




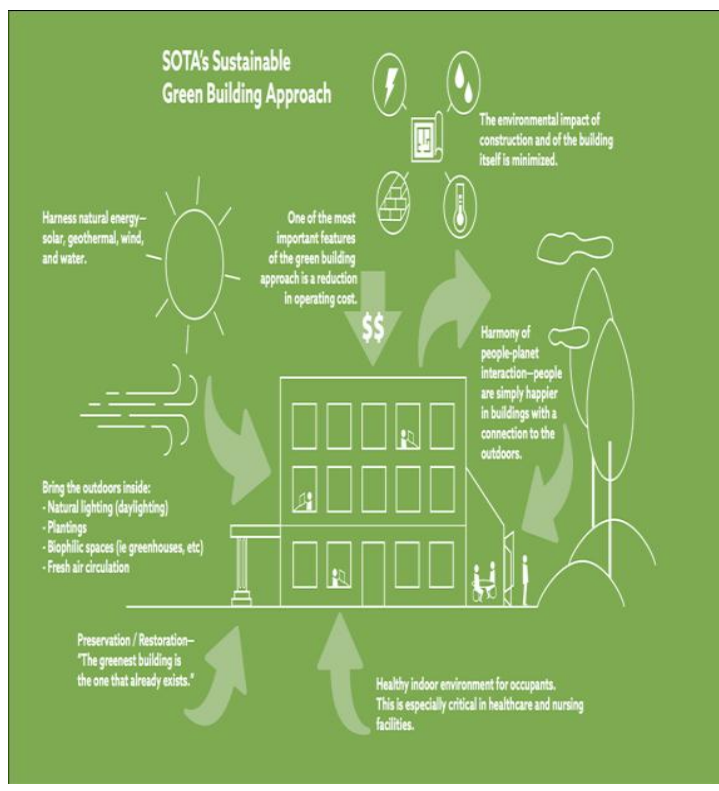

Image: www.sotaconstruction.com

techniques focusing on data publishing and talk about back- ground knowledge and also problems of privacy preserving data publisng.

\section{Traditional architectural Elements}

The climate of Bangladesh and South East Asian region is that of a tropical /monsoon. Traditional architecture of this region or that of any other region tells the language of that place and is a byproduct of hundreds of years of their adaptation to the soil, wind and custom of that area.

In search of roots of Bengal, a list of traditional architectural elements is as following:

i. Waterfront (ghaat): waterfront has a cultural value where people swim, socialize and do various activities. Waterfront can be part of a homestead or a public amenity.

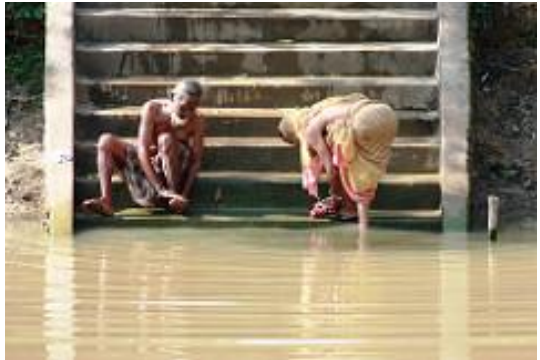

Result: helps to achieve a cooler microclimate

ii. Vegetation: increasing green vegetation shrubs and tress in a homestead can reduce temperature upto 4 degree celcius.

Result This helps in achieving a good micro climate

iii. Perforated Screen (Jali): Jali is an architectural element of the South East Asia region which is vanishing with time in modern buildings. Even till the 80's buildings had jail in the form of ventilators.

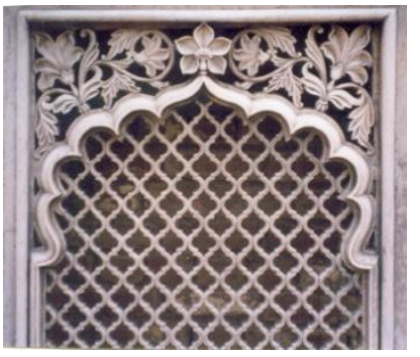

iv. Extended veranda corridor/ Entry Foyer (Dawa): this space is atypical to a village residence of Bangladesh and the Indian sub continent, a space which is often used for guests or doing light work like weaving.

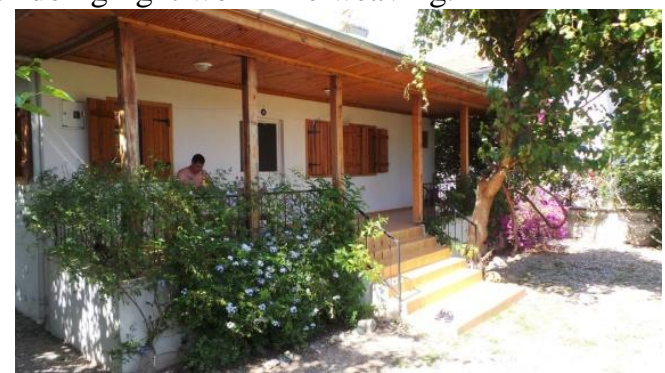

v. Courtyards: Courtyards have long existed in sub continental rural areas and have also found place as Mughal courtyards.

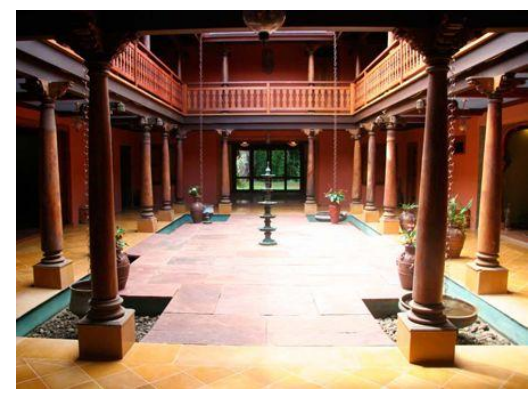

vi. Overhead roof (chhajja): reduction of heat island by the use of overhead shading device.

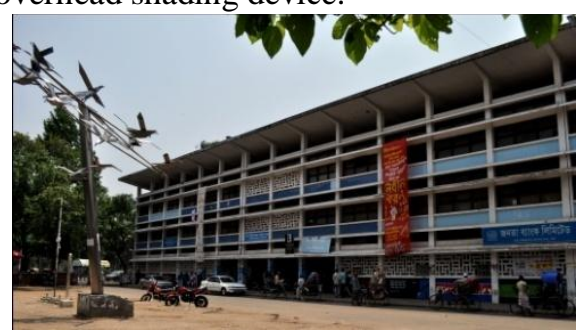

TSC building is a good example of venture effect in double layered overhead roof.

vii. Wooden Façade treatment (khirki) :wooden window panels have become non-existent in Bangladesh with the rise in extinction of old buildings. Wooden window panels keep the house cooler in comparison to its glass counterpart.

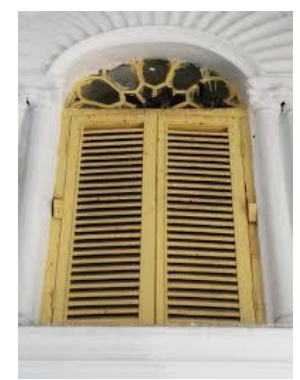

viii. Teracotta: found in the Bengal region as early as $700 \mathrm{AD}$ at Paharpur, Bangladesh. Teracotta walls and sculptures have been present in temples of the region.

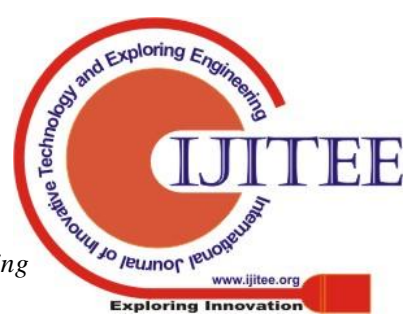




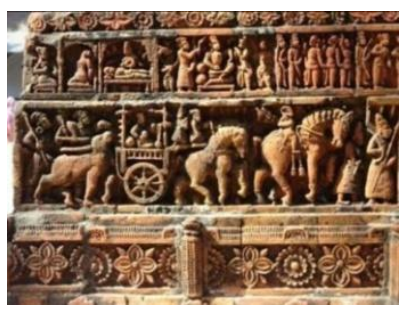

Fig: Kantaji Mandir,Dinajpur,Bangladesh

A Case Study: Meghna Residence, Dhaka, Bangladesh

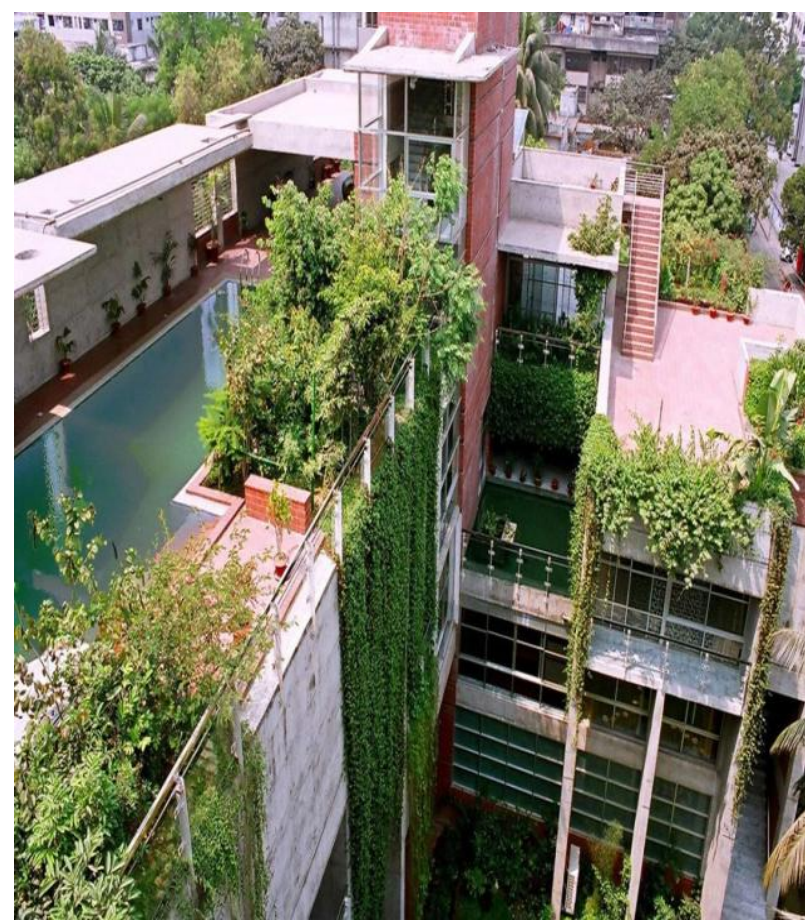

Photo courtesy: Hassan SaifuddinChandan

Meghna Residence is a single extended family house situated in on a bustling street of Dhanmondi, Dhaka, Bangladesh. The house has been conceived in three layers: its surrounding context, the climate and traditional typology. The courtyard is the predominant traditional element of the project along with a waterfront (ghaat), ample vegetation and water body.

This building has been taken under consideration for survey to achieve a wholesome feedback of the dwellers of a house in the heart of the chaotic city with traditional architectural elements intrinsic to Bengali culture.

The designer (Shatotto - Architecture for Green Living) intends to unravel the lost history and heritage of Bangladesh and revive the missing links of its urban and rural culture. In an attempt to bridge the gap between architectural values of the past and present, this family residence was born.

Dweller (Ashraf) states about the impact of flora and fauna in the residence. He says that many birds come around in the different seasons specially on the rooftop garden and water body. They come to have fruits and water. He adds that it becomes difficult to maintain the swimming pool because of the birds littering.

Dweller (Mr. Kamal) has reported to become nostalgic to his early days in village when he sits in the calm rooftop area adorned with green and a water body, amidst the chaotic city.

\section{CONCLUSION}

Salutogenesis encompasses the wellbeing of human beings which embodies both mental and physical health. Generating environments that enhance wellbeing for its dwellers is the aim of the modern day green building and salutogenic architecture. Reinstalling the lost cultural inferences in architecture which have time- tested acceptability for generations, enhances the wellbeing for the dwellers in present times.

\section{LIMITATIONS AND DELIMINATIONS:}

Only one sample survey has been conducted. This leaves scope for researchers to collect more information from dwellers in both vernacular architectural structures and concrete city structures in the future. There is scope for further study on more traditional architectural elements found in Bangladesh and the Indian sub-continent region which is not limited to only those listed in this study.

\section{RECOMMENDATIONS}

Salutogenesis is being incorporated in health care premises, but I feel that this principle needs to be made an integral part of all architectural edifices. Practitioners need to adopt the concept of salutogenesis in their work. Cultural elements of the region need to be given importance in design decision.

\section{ACKNOWLEDGEMENT}

1. I would like to show my gratitude to Dr Saiful Haque (Director, Institute of Energy, University of Dhaka, Bangladesh) for his supervision and guidance throughout the study.

2. I thank Aurélien Lemonier (Architect and Curator, Centre Pompidou, France) for his reflections during the initial conceptualization phase.

3.I am grateful to Dipon Bose (Architect) for his contribution in data collection in the survey of a case study.

\section{REFERENCES}

1. Amer,M.B.K.B. (2016, September 7) "Courtyards, Influence of the Indian Traditional Architectural Element on Community Interactions" Retrieved from https://www.gounesco.com/courtyards-influence-of-theindian-traditional-architectural-element-on-communityinteractions/

2. Golembiewski, Jan A. (2012) Salutogenic design: The neurological basis of health-promoting environments. World Health Design: Architecture, Culture, Technology, 5(3), pp. 62-69.

3. Heimburg,D.V. ( 2010) "Public Health and Health Promotion: A Salutogenic Approach" Master Degree In Health Science, Norwegian University Of Science And Technology, Ntnu.

4. Jadhav,R. (2007,June) "Green Architecture in India: Combining Modern Technology with Traditional Methods" $\quad$ Retrieved from https://unchronicle.un.org/article/green-architecture- 
india-combining-modern-technology-traditional-methods

5. Lucas,R.M. et all, (2014,December 1) "Vitamin D and Immunity Retrieved" from https://www.ncbi.nlm.nih.gov/pmc/articles/PMC4251419 /

6. Mowla, Qazi A. "An Appraisal of Architecture in Dhaka with Reference to its Thermal Performance". In Regionalism in Architecture, edited by Robert Powell. Singapore: Concept Media/Aga Khan Award for Architecture, 1985.

7. Sinha,A.\& Gupta,R. \& Kutnar,A. "Sustainable Development and Green Buildings" Retrieved from file:///C:/Users/dh/Downloads/Drv_Ind_Vol_64_1_Sinha $\underline{\% 20(1) . p d f}$ 